\title{
SIETE CARTAS INÉDITAS DE YUCATÁN: COMUNICACIÓN PRIVADA ENTRE MAYAS Y ESPAÑOLES, Y EXPLOTACIÓN ILEGAL DEL AÑIL EN EL SIGLO XVI
}

\author{
Caroline Cunill \\ Université du Maine
}

\begin{abstract}
Resumen: El trabajo analiza un conjunto de cartas inéditas que intercambiaron particulares, tanto indígenas como españoles, en el Yucatán del siglo xvı. Estas misivas se conservaron porque el defensor de indios Francisco Palomino las adjuntó, como documentos probatorios, a un memorial que envió al rey de España en 1576 para denunciar el uso, tan excesivo como ilegal, de la mano de obra maya en la explotación del añil, en pleno auge en aquellos años. Las cartas ofrecen, por lo tanto, la incomparable ventaja de acercarnos a uno de los campos históricos de más difícil acceso, el de la comunicación escrita privada en el seno del Imperio hispánico. Este notable interés se ve reforzado por el hecho de que cinco de las siete misivas estaban dirigidas a caciques indígenas, de modo que el material nos permite también reflexionar sobre las modalidades de comunicación privada entre mayas y españoles a principios del periodo colonial.
\end{abstract}

Palabras clave: comunicación privada, discurso colonial, mayas, Yucatán.

AвstRACT: The present paper examines a group of letters that Mayas and Spaniards exchanged in sixteenth century Yucatán. These missives have survived because the Defensor de Indios Francisco Palomino joined them, as proof documents, to a memorial he sent to the king of Spain in 1576 in order to denounce the excessive and illegal use that the Yucatecan colonists made of Maya workers in the indigo plant's production. This group of seven letters offers the incomparable opportunity to better understand one of the historical fields of more difficult access, the private written communication in the Spanish Empire. This notable interest is reinforced by the fact that five of those letters were addressed to indigenous governors, so that one of the paper's objectives will consist in highlight the modalities of epistolary communication between Mayas and Spaniards in Colonial Yucatán.

KeYwords: private communication, colonial discourse, mayas, Yucatán.

ReCEPCIÓn: 2 de abril de 2014.

ACEPTACIÓN: 25 de julio de 2014. 



\title{
SIETE CARTAS INÉDITAS DE YUCATÁN: COMUNICACIÓN PRIVADA ENTRE MAYAS Y ESPAÑOLES, Y EXPLOTACIÓN ILEGAL DEL AÑIL EN EL SIGLO XVI"
}

\author{
Caroline Cunill
}

Université du Maine

\section{Introducción}

Los estudios recientes sobre el papel que desempeñaron los intermediarios en el Nuevo Mundo han puesto de manifiesto el carácter endeble de las categorías tradicionalmente utilizadas para analizar las sociedades multiétnicas, insistiendo en los numerosos lazos biológicos, económicos, políticos y culturales que unían a los distintos sectores sociales que conformaban el Imperio hispánico. ${ }^{1}$ Como lo han mostrado los especialistas de la Nueva Filología, aquellos intercambios tuvieron evidentes consecuencias en la evolución de los idiomas hablados en América. ${ }^{2}$ No obstante, hasta la fecha de hoy los estudios histórico-linguísticos se han enfocado esencialmente en la comunicación oficial entre los grupos indígenas y las autoridades hispanas. ${ }^{3} \mathrm{Y}$ es que, a diferencia de la documentación notarial, la conservación de fuentes extraoficiales no fue sistemática, sino el resultado de

\footnotetext{
"Quisiera agradecer a Mario Humberto Ruz y a Rodrigo Martínez Baracs por sus atentas lecturas del manuscrito y por sus valiosos comentarios.

${ }^{1}$ Yanna Yannakakis, The Art of Being in Between. Native Intermediaries, Indian Identity, and Local Rule in Colonial Oaxaca. Durham y London: Duke University Press, 2008.

${ }^{2}$ Véanse, entre otros, James Lockhart y Frances Karttunen, Nahuatl in the Middle Years: Language Contact Phenomena in Texts of the Colonial Period. Berkeley: University of California Press, 1976 y James Lockhart, Nahuas and Spaniards: Postconquest Mexican History and Philology. Stanford: Stanford University Press, 1991. Sobre La Nueva Filología como corriente historiográfica, consúltese Matthew Restall, "A History of New Philology and the New Philology in History", Latin American Research Review, XXXVIII (1): 113-134.

${ }^{3}$ Para el caso de Yucatán, véanse Matthew Restall, The Maya World. Yucatec Culture and Society, 1550-1850. Stanford: Stanford University Press, 1997; Tsubasa Okoshi Harada, "Los Xiu del siglo xvl: una lectura de dos textos mayas coloniales”, Mesoamérica, XXXIX: 225-253; Sergio Quezada y Tsubasa Okoshi Harada, Los papeles de los Xiu de Yaxá, Yucatán. México: Universidad Nacional Autónoma de México, 2001; William F. Hanks, Converting Words. Maya in the Age of the Cross. Berkeley: University of California Press, 2010, sobre un importante conjunto de textos escritos en lengua maya yucateca en el periodo colonial.
} 
circunstancias imprevisibles. De este modo, la única forma de conocer los intercambios privados entre españoles, indígenas y castas en la América hispana consistió, por lo general, en utilizar referencias indirectas. ${ }^{4}$

En esas circunstancias, mi sorpresa sólo pudo igualar mi satisfacción cuando encontré en el Archivo General de Indias de Sevilla un conjunto de siete misivas que formaban parte de un acto de comunicación privada entre particulares del Yucatán del siglo xvi. Recordé las palabras del investigador Benedict Warren, quien dijo sentirse "afortunado" por localizar 10 cartas que un encomendero de Michoacán envió a su mayordomo entre 1533 y 1534, ya que, según este autor, se trataba de un hallazgo excepcional por su naturaleza privada. ${ }^{5}$

Un valor añadido de las misivas del Archivo General de Indias radica en el hecho de que cinco de ellas estaban dirigidas a gobernadores mayas. Así pues, las cartas no sólo brindan novedosos datos sobre el uso de la mano de obra indígena en la explotación del añil, sino que también permiten reflexionar sobre los intercambios epistolares que se dieron entre mayas y españoles en la época colonial.

Estos textos pueden ponerse en perspectiva con la carta en náhuatl escrita en 1564 por Juan Hernández, cacique del pueblo de Teotitlán-Copilco, a su "Muy caro amigo don Jhoan de Amatitán", que localizó Mario Humberto Ruz en la probanza de Alonso Gómez de Santoyo, teniente de gobernador y justicia mayor en la provincia de Tabasco. ${ }^{6}$ Tampoco es ocioso recordar las 37 misivas que enviaron al visitador don Francisco Gómez de Lamadriz los representantes de varias comunidades indígenas guatemaltecas para concertar con él una alianza en contra de la Audiencia de Guatemala a finales del siglo xvI. ${ }^{7}$ Todo ello parece sugerir que, en algunas ocasiones, las alianzas fundadas en intereses comunes rebasaron las fronteras de la etnicidad, imponiéndose la fuerza del orden económico a la rigidez de las jerarquías étnicas. Por otro lado, dejan entrever que esta situación tuvo consecuencias en el campo linguí́stico, ya que los autores de las citadas mi-

\footnotetext{
${ }^{4}$ Véanse Cecilia Brain, "Aprendizaje de lenguas indígenas por parte de españoles en Nueva España en los primeros cien años después de la conquista”, Colonial Latin American Review, XIX (2): 279-300; Robert C. Schwaller, "The Importance of Mestizos y Mulatos as Bilingual Intermediaries in SixteenthCentury New Spain" y Martin Nesvig, "Spanish Men, Indigenous Language, and the Informal Interpreters in Postcontact Mexico", Ethnohistory, LIX (4): 713-738 y 739-764.

${ }^{5}$ Benedict J. Warren, La administración de los negocios de un encomendero de Michoacán. México: Secretaría de Educación Pública, 1984. En el campo de la literatura epistolar extraoficial americana también cabe mencionar las obras siguientes: James Lockhart y Enrique Otto, Letters and People of the Spanish Indies. Cambridge: Cambridge University Press, 1976; Enrique Otto, Cartas privadas de emigrantes a Indias 1540-1616. Sevilla: Escuela de Estudios Hispanoamericanos, 1988; José Luis Martínez, El mundo privado de los emigrantes en Indias. México: Fondo de Cultura Económica, 1992 y Mariano Franco Figueroa, "Cartas de mujeres en documentos americanos coloniales", Boletín de Filología, XLVI (2): 59-84.

${ }^{6}$ Mario Humberto Ruz, "La última conquista: Tecpan Cimatán, 1564", Tierra y Agua, 4: 7-23. El valor añadido de la carta localizada por Ruz es el hecho de que se trató de un acto de comunicación interna, esto es, realizado entre dos comunidades indígenas de Tabasco en el siglo xvı.

${ }^{7}$ María del Carmen León Cázares, Un levantamiento en nombre del Rey Nuestro Señor. Testimonios indígenas relacionados con el visitador Francisco Gómez de Lamadriz. México: Universidad Nacional Autónoma de México, Centro de Estudios Mayas, 1988.
} 
sivas crearon "otro discurso", que se caracteriza por un mayor grado de compromiso entre las culturas europea e indígena. Pero este discurso "marginal" no fue menos operativo que el discurso "oficial", ya que no sólo reflejó otra vertiente de la realidad colonial, sino que moldeó dicha realidad hasta cierto punto. ${ }^{8}$ En definitiva, quisiéramos mostrar cómo las siete misivas ponen de manifiesto la porosidad de las categorías étnicas coloniales y los límites de su eficiencia sobre la compleja realidad multiétnica que éstas pretendían controlar.

\section{Breve descripción del conjunto documental}

La historia de los documentos resulta a veces sorprendente: tal es el caso de las siete misivas del Archivo General de Indias que se estudian a continuación. En efecto, estos textos no debieron conservarse, y menos aún entre los papeles oficiales de la monarquía hispana, ya que se trataba de un acto de comunicación privado y cuyo contenido, además, atestiguaba actividades prohibidas por las autoridades metropolitanas, de forma que en ningún modo sus autores hubiesen deseado que cayesen en las manos del rey Felipe II y de su Consejo. Pero las misivas fueron interceptadas por el defensor de indios de Yucatán, Francisco Palomino, quien juzgó oportuno realizar una copia de las mismas y adjuntarlas, como documentos probatorios, al memorial que mandó al monarca el 10 de noviembre de 1576. Con ello, el defensor pretendía dar a conocer los abusos que tanto los encomenderos como los oficiales reales de Yucatán cometían contra los mayas para beneficiar el añil, con el beneplácito del gobernador Francisco Velázquez de Gijón, que también estaba interesado en aquel próspero negocio. Pero, si bien el memorial de Francisco Palomino se conoce desde la década de los ochenta, puesto que la investigadora Sara Miller lo citó en un artículo centrado en dicho defensor, las cartas permanecieron inéditas hasta la fecha de hoy, por haberse traspapelado en el legajo 100 de la sección "Audiencia de México" del mencionado archivo. ${ }^{9}$

Ahora bien, el expediente en el que se encuentran las misivas se compone de tres folios escritos en un solo lado y encabezados por la mención siguiente: "Este es un trasunto de unas cartas que los de dentro en ellas contenidas escribieron a los caciques. Va para que su Majestad lo vea". Pese a la ausencia de indicaciones geográficas precisas en este descriptivo, la referencia a actores indígenas llamó mi atención, de modo que empecé a leer las misivas. No tardé mucho en

\footnotetext{
${ }^{8}$ Michel Foucault, El orden del discurso. Barcelona: Tusquets, 1970.

${ }^{9}$ Sara Miller, "Francisco Palomino, protector y defensor de los indígenas", Mesoamérica, IX: 143. Memorial de Francisco Palomino al rey, Mérida, 10 de noviembre de 1576. Archivo General de Indias (en adelante AGI), México 100, R. 4, 4 fols. Traslado de unas cartas que los de dentro en ellas contenidas escribieron a los caciques. AGI, México 100, R. 4, 3 fols. Se ofrece una transcripción de las misivas en el apéndice documental. Para facilitar la lectura del artículo citaré estos documentos con el número que se les puso en dicha transcripción, el cual corresponde al orden en el que las cartas se encontraban en el expediente original.
} 
vincularlas con el memorial de Francisco Palomino del 10 de noviembre de 1576, puesto que, en aquel documento, el defensor se refería a unas cartas que decía haber juntado a su escrito para que constara al monarca de las exacciones e irregularidades que cometían los españoles contra los mayas en la explotación del añil. Por otro lado, en el expediente se precisaba que la transcripción de las misivas había sido realizada el 24 de octubre de 1576, fecha que se aproximaba a la del memorial de Francisco Palomino. Finalmente, los nombres de los encomenderos y de los oficiales reales, así como el de los gobernadores mayas y de los pueblos indígenas coincidían en ambos documentos.

En consecuencia, se puede argüir que el texto de Francisco Palomino ofrecía, en realidad, una esclarecedora glosa de las cartas, al proporcionar no sólo la identidad de los actores involucrados, sino también la naturaleza de los lazos familiares y clientelares que los unían entre sí. Además, el defensor mencionaba una cédula del 4 de enero de 1575 en la que se reiteraba la prohibición de que los encomenderos residiesen en las comunidades indígenas que les estaban encomendadas y que tuviesen "tratos y granjerías" con "sus" indios. ${ }^{10}$ Este documento, cuya transcripción fue realizada en fechas similares a la de las cartas, esto es, el 27 de octubre de 1576, también se encuentra en el legajo 100 de la sección "Audiencia de México" del Archivo General de Indias. ${ }^{11}$ Todo ello parece indicar, por ende, que el memorial, las misivas y la cédula formaban parte de un conjunto documental cuyo objetivo consistía en denunciar la explotación de los mayas en el cultivo del añil y en crear, asimismo, un auténtico impacto en el monarca y su Consejo.

Concretamente, las cartas se reparten en tres grupos. Cada uno de ellos está separado por una autentificación de Francisco de Orozco, el notario apostólico encargado de transcribir los documentos, y por la firma de dos testigos, Alonso Palomino el Mozo, el hijo de Francisco Palomino, y Francisco de Acebedo. ${ }^{12}$ Se puede observar que esta división se realizó en función de la identidad de los emisores y de los destinatarios de las cartas. En efecto, el primer grupo cuenta con tres misivas escritas por el encomendero Francisco de Arceo (\#1) y por su hijo Fernando de Arceo en abril de 1576 (\#2 y 3); iban dirigidas al gobernador

${ }^{10}$ Acerca de este marco normativo, véanse Manuela Cristina García Bernal, "Indios y españoles en Yucatán: Utopía y realidad del proyecto colonizador”, Congreso de Historia del Descubrimiento, vol. II, pp. 387-427. Madrid: Real Academia de Historia, 1992 y Gabriela Solís Robleda, Bajo el signo de la compulsión: el trabajo forzoso en el sistema colonial yucateco, 1540-1730. México: Instituto Nacional de Antropología e Historia y Centro de Estudios Superiores en Antropología Social, 2003.

11 Testimonio de la real cédula de Su Majestad sobre que los encomenderos de la provincia de Yucatán no se sirvan de sus encomendados. Va para que Su Majestad lo vea. AGI, México 100, R. 4. La cédula en cuestión lleva el título siguiente: "Real cédula al gobernador de Yucatán para que prohíba que los encomenderos residan en sus pueblos de encomienda y tengan tratos con sus encomendados, San Lorenzo, 4 de enero de 1575".

${ }^{12}$ Francisco Palomino tuvo un hijo llamado Alonso Palomino, que lo acompañó en algunos viajes a la metrópoli y acabó siendo defensor de indios en Tabasco hacia 1580. Caroline Cunill, "Los defensores de indios de la alcaldía mayor de Tabasco (siglo xvl)”, Historia Mexicana, LXII (2): 551-590. 
indígena del pueblo de Xanaba, don Martín Tun. El segundo se compone de una carta del encomendero Cristóbal Sánchez a Juan González, el español que gestionaba la estancia de añil del gobernador don Francisco Velázquez de Gijón (\#4) y de una nota que Juan González, a su vez, mandó al citado gobernador (\#5). Cabe recordar, en efecto, que, según el defensor Francisco Palomino, Velázquez de Gijón poseía una explotación en las cercanías de la ciudad de Mérida, aunque éste daba "otros colores para decir que no es suy[a], sino de un hombre que reside en esta hacienda que se dice Juan González, mozo soltero, y que, porque en España le hizo buena obra, [el gobernador] le favorece". ${ }^{13}$ Finalmente, el último grupo está conformado por dos misivas que los oficiales reales de Yucatán, Pedro González y Francisco Pacheco, mandaron a don Pedro Pech, gobernador del pueblo de Telchac, en septiembre de 1576 (\#6 y 7). ${ }^{14}$

Pese a la diversidad de actores implicados, estos documentos se caracterizan por su gran unidad temática, ya que todos giran en torno a la explotación de la mano de obra indígena en la granjería del añil: su reparto, rotación, remuneración y sustento. Por otro lado, cabe señalar que, por mucho que dos de los seis emisores y uno de los tres destinatarios fuesen representantes del Imperio - los oficiales reales y el gobernador de Yucatán-, aquellos intercambios epistolares son extraoficiales, ya que tratan de la gestión de negocios privados, e incluso ilegales. En consecuencia, las siete misivas comparten un estilo distinto al que suele encontrarse en la correspondencia oficial, caracterizándose éste por una mayor concisión y cierta tendencia al pragmatismo y a la informalidad. ${ }^{15}$

De hecho, la carta cuyo tono más se acerca al de los textos notariales es la que está dirigida a don Francisco Velázquez de Gijón (\#5), ya que, si bien su emisor trata al gobernador como a un "empresario", no deja de tener en mente su posición jerárquica, de ahí que se cuide de respetar la mayoría de las pautas estilísticas características de los documentos oficiales. Sin embargo, sería erróneo considerar que las misivas destinadas a los caciques mayas carecen de elementos retóricos. Al contrario, los autores de los textos \#1-3 y \#6-7 se valieron de una estrategia discursiva propia, en la que destacan claras muestras de deferencia, así como el uso de un trato fraterno para con los gobernadores mayas. Y es que, como se verá más adelante, los colonos españoles eran conscientes del papel fundamental que desempeñaban las autoridades indígenas en el proceso de extracción de la mano de obra local.

\footnotetext{
${ }_{13}^{13}$ Memorial de Francisco Palomino al rey, Mérida, 10 de noviembre de 1576, cit.

${ }^{14}$ Según Sergio Quezada, don Pedro Pech era gobernador del vecino pueblo de Kiní, administrado, al igual que Telchac, por la Corona. El autor también señala que, en 1571, su hermano don Luis Pech solicitó ser nombrado como coadjutor en la gubernatura. S. Quezada, Pueblos y caciques yucatecos, 1550-1580, p. 152. México: El Colegio de México, 1993.

${ }^{15}$ Sobre aspectos formales del español escrito en España y América, véanse Wulf Oesterreicher, "Textos entre inmediatez y distancia comunicativas. El problema de lo hablado escrito en el Siglo de Oro", Historia de la lengua española, pp. 729-769, Rafael Cano Aguilar (coord.). Barcelona: Ariel, 2004; Wulf Oesterreicher, Eva Stoll y Andreas Wesch (eds.), Competencia escrita, tradiciones discursivas y variedades lingüísticas. Aspectos del español europeo y americano en los siglos xVI y XVII. Tübingen: Nar, 1998.
} 


\section{Intercepción y traslado de las cartas}

La primera pregunta que viene a la mente, tratándose de un acto de correspondencia privada, es cómo Francisco Palomino logró interceptar unas cartas cuyo contenido, además, perjudicaba a las personas involucradas en aquellos negocios ilegales. En su memorial, el mismo defensor esclarece en qué condiciones se hizo con cuatro de las siete misivas. Según él, la carta de Cristóbal Sánchez y la nota de Juan González que figuraba a su espalda (\#4 y 5) vinieron "a mano del gobernador [don Francisco Velázquez de Gijón]”, pero éste "se descuidó”, de modo que la misiva "se cayó en el suelo" y el encomendero Antonio de Bohórquez, estando "a esta sazón [...] preso en las Casas Reales, dio con ella” y la entregó al defensor. ${ }^{16}$ Si seguimos la versión de Palomino, la intercepción de este documento se debiera, por lo tanto, al azar. Pero un detalle pone en tela de juicio el supuesto carácter fortuito del hallazgo. Y es que, en su misiva, Cristóbal Sánchez decía cómo enviaba indios del pueblo de encomienda del citado Antonio de Bohórquez a trabajar en la estancia de añil del gobernador de Yucatán (\#4). ${ }^{17}$ Por consiguiente, parece que Velázquez de Gijón se estaba aprovechando del encarcelamiento de Bohórquez para servirse de los indígenas que le estaban encomendados a éste. Si bien este elemento no esclarece las circunstancias precisas en las que la carta fue interceptada, sí se entienden los motivos que pudieron empujar a Bohórquez a denunciar al gobernador. El encarcelamiento del encomendero también revela la existencia de una enemistad con don Francisco Velázquez de Gijón.

Francisco Palomino explica, asimismo, que el tercer grupo de misivas, que fueron escritas por los oficiales reales de Yucatán, le fue entregado por el gobernador de Telchac don Pedro Pech (\#6 y 7), dato que muestra que algunos mayas conocían el cargo de defensor de indios, así como la identidad de su titular, puesto que don Pedro fue capaz de localizarlo en la ciudad de Mérida. No queda duda de que el cacique era consciente del daño que estos documentos podrían ocasionar a los actores involucrados y, de hecho, no fue el único maya en quejarse ante Palomino. En efecto, en su memorial de 1576, el defensor afirmaba que su conocimiento de los abusos cometidos contra los mayas se debía a que "los mismos indios de la provincia se me han quejado de ello, diciendo que para la estancia del gobernador [Velázquez de Gijón] les saca de ciento en ciento". ${ }^{18}$

En consecuencia, se puede arguiir que las circunstancias en las que fueron interceptadas las cartas ponen de manifiesto las fuertes tensiones que recorrían al grupo de actores (españoles e indios) implicados en la explotación del añil en la provincia de Yucatán. Por un lado, la acuciante demanda de mano de obra indígena que exigía el cultivo y la producción de este material tintóreo generaba una

${ }^{16}$ Ibid.

17 Antonio de Bohórquez era encomendero de los pueblos de Suma y Bokabá. Manuela Cristina García Bernal, Población y encomienda en Yucatán bajo los Austrias. Sevilla: Escuela de Estudios Hispanoamericanos, p. 509, 1978.

${ }^{18}$ Memorial de Francisco Palomino al monarca, Mérida, 10 de noviembre de 1576, cit. 
encarnizada competencia entre los colonos, quienes estaban dispuestos a valerse de cualquier medio para captar a los trabajadores necesarios para desarrollar aquella lucrativa actividad. Por otro lado, la denuncia presentada por un gobernador maya revela la fragilidad de la alianza que trataron de entablar los españoles con las autoridades indígenas para controlar la mano de obra. En efecto, aunque las misivas, en su conjunto, parecen atestiguar la existencia de una comunicación frecuente entre ambos grupos étnicos, así como cierta confluencia de intereses en torno a la explotación de la mano de obra indígena, en ocasiones los caciques dejaron de cooperar con los colonos.

Ahora bien, ¿por qué el defensor decidió acudir al notario apostólico de Yucatán para que éste realizara la copia de las misivas, en vez de dirigirse al escribano real, como hubiese sido lógico tratándose de un asunto civil? Cabe señalar que el traslado de la cédula de 1575, que Francisco Palomino también adjuntó a su memorial de 1576, fue sacado por el escribano de gobernación Pedro de Herrera, en presencia de los testigos Alonso de Arévalo, Hernando de San Martín y Juan López de Moya. ${ }^{19}$ En realidad, el mismo defensor explica que no quiso arriesgarse a que dicho escribano divulgara sus denuncias al gobernador de Yucatán, puesto que éste, al estar involucrado en los negocios del añil, hubiera podido obstaculizar la circulación de la información hacia el monarca. ${ }^{20}$ Así pues, Palomino se aprovechó de la amistad que tenían con el obispo fray Diego de Landa para recurrir a los servicios del notario apostólico Francisco de Orozco. De hecho, en la autentificación de las misivas, éste confirmó la versión brindada por el defensor, al declarar que intervino "de mandamiento del muy Ilustre y Reverendo Señor don fray Diego de Landa, mi Señor Obispo [...] y de pedimento de Francisco Palomino, defensor de los naturales [...], en cuyo poder quedan los originales para informar de ello a Su Majestad y a su Real Consejo". El notario apostólico agregó que no se pidió la copia al escribano real "por los inconvenientes que de manifestarlo podría suceder y porque podrían impedirlo y buscar los medios para que lo susodicho no tuviese efecto". ${ }^{21}$

Es sabido que la alianza entre Francisco Palomino y los franciscanos era bastante antigua, dado que, ya en 1569, el provincial fray Francisco de la Torre influyó en su elección para el cargo. ${ }^{22}$ Del mismo modo, el notario apostólico Francisco de Orozco figura entre los testigos que el defensor presentó en su probanza de 1572 para que el Consejo de Indias le confirmara en su oficio. En aquella ocasión, Orozco aseguró que Palomino "acudió muchas veces" a él para que lo "alumbr[ara] con lo que sabía, entendía y alcanzaba" en los negocios indígenas. ${ }^{23}$

19 Testimonio de la real cédula y provisión de Su Majestad sobre que los encomenderos de la provincia de Yucatán no se sirvan de sus encomendados, cit.

${ }^{20}$ Memorial de Francisco Palomino al monarca, Mérida, 10 de noviembre de 1576, cit.

${ }^{21}$ Apéndice documental.

${ }^{22}$ Carta de fray Francisco de la Torre al rey, 9 de marzo de 1569. AGI, México 367, fols. 116-122.

${ }^{23}$ Información presentada por Francisco Palomino, vecino de la ciudad de Mérida, sobre que se revoque cierta cédula y se le vuelva el oficio de defensor de los indios (1571-1572). AGI, México 99, R. 1. 
En cuanto al obispo Landa, no se contentó en facilitar al defensor los servicios de su notario para que las denuncias llegaran al rey, sino que también se declaró públicamente determinado a poner "pena de descomunión a todas las personas que hacen añil y a mandar que no los confiesen". Según el prelado, en efecto, no bastaban "las cédulas y provisiones de Vuestra Majestad en que manda que a los indios para servir en el añil no les hagan fuerza". ${ }^{24}$ Queda claro, por lo tanto, que la intervención de fray Diego resultó decisiva en las gestiones del defensor a favor de los mayas.

\section{Una compleja red de intereses}

La primera impresión que se desprende de la lectura de las cartas es la compleja organización que había alcanzado el negocio del añil en el Yucatán de la década de $1570 .{ }^{25}$ En efecto, son nada menos que 12 los pueblos mayas citados en estos documentos y 25 los actores históricos involucrados (cuadro 1). A nivel geográfico, se distinguen tres zonas, que corresponden al contenido de cada grupo de cartas. Primero se encuentra el eje formado por Acanceh y Xanaba, pueblos de encomienda de Francisco de Arceo, mencionados en los textos \#1, 2 y 3. Las comunidades de Telchac y Dzemul, administradas por la Real Corona, conformaban la segunda zona y aparecen en las misivas de los oficiales reales (\#6 y 7). ${ }^{26}$ Finalmente, los documentos \#4 y 5 mencionan Cacalchen, Temozon, Teya, Canaçi (Kanasin), Quitilcum (Citilcum), Bocaba (Bokaba), Tixcochoh (Tixkoxoh) y Tixculum. Esta lista se alarga de tomarse en cuenta Tepakan y Tekanto, Temax y Suma, pueblos encomendados, respectivamente, en Cristóbal Sánchez, Juan de Sosa y Antonio de Bohórquez, también citados en estas misivas. ${ }^{27}$

\footnotetext{
${ }^{24}$ Memorial de Francisco Palomino al rey, Mérida, 10 de noviembre de 1576, cit. "Descomunión" es un sinónimo de "excomunión". Esta alianza se volvió a concretar en 1578, cuando el obispo prestó 3,000 pesos a Palomino para que éste pudiese librarse de sus acreedores, pagar las condenaciones de su juicio de residencia y financiar un viaje a la Corte para defenderse de las acusaciones de sus detractores ante el monarca y su Consejo. Caroline Cunill, "Negocios y justicia: Francisco Palomino, defensor de los mayas de Yucatán (1569-1586)", Temas americanistas, XX: 8.

${ }^{25}$ Sobre esta materia tintórea, véanse María Justina Sarabia Viejo, La grana y el añil. Técnicas tintóreas en México y América Central. Sevilla: Escuela de Estudios Hispanoamericanos, 1994; Manuel Rubio Sánchez, Historia del añil o xiquilite en Centroamérica. San Salvador: Dirección de Publicaciones del Ministerio de Educación, 1976; François Chevalier, El añil, su artesanía actual en el Departamento de Chalatenango. San Salvador: Departamento de Investigaciones del Patrimonio Cultural, 1976; Mario Humberto Ruz, "El añil en el Yucatán del siglo xv", Estudios de Cultura Maya, XII: 111-156; Manuela Cristina García Bernal, op. cit., pp. 440-460; Caroline Cunill, Los defensores de indios de Yucatán y el acceso de los mayas a la justicia colonial, 1540-1600, pp. 281-294. Mérida: Universidad Nacional Autónoma de México, Centro Peninsular en Humanidades y Ciencias Sociales, 2012.

${ }^{26}$ Manuela Cristina García Bernal, op. cit., pp. 202-203.

27 Ibid., fols. 509, 513 y 515. Según el defensor, Cristóbal Sánchez tenía una estancia de añil en Tepakan. Memorial de Francisco Palomino al monarca, Mérida, 10 de noviembre de 1576, cit.
} 


\begin{tabular}{|c|c|c|c|c|c|}
\hline \multicolumn{6}{|c|}{ 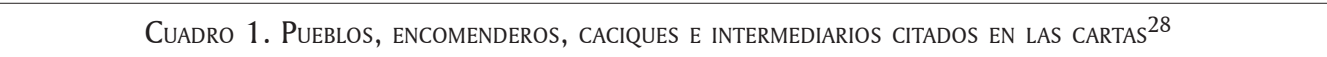 } \\
\hline Pueblos & Encomenderos & Otros españoles & Caciques & Intermediarios & Cartas \\
\hline $\begin{array}{c}\text { Xanaba } \\
\text { [Xenaba] }\end{array}$ & $\begin{array}{l}\text { Francisco de Arceo } \\
\text { Fernando de Arceo }\end{array}$ & & $\begin{array}{c}\text { Don Martín } \\
\text { Tun }\end{array}$ & $\begin{array}{c}\text { Baltasar Tun } \\
\text { Martín Dzabanal }\end{array}$ & $\begin{array}{c}\# 1, \# 2, \\
\# 3\end{array}$ \\
\hline Acanceh & $\begin{array}{l}\text { Francisco de Arceo } \\
\text { Fernando de Arceo }\end{array}$ & & & $\begin{array}{c}\text { Agustín Chan } \\
\text { (escribano) }\end{array}$ & $\# 2, \# 3$ \\
\hline Çique [Saci] & [Baltasar Gallego] & & & Francisco Chan & $\# 2$ \\
\hline $\begin{array}{c}\text { Canaçi } \\
\text { [Kanasin] }\end{array}$ & [Antonio de Yelves] & & & & $\# 4$ \\
\hline Temozon & $\begin{array}{c}\text { [Andrés González } \\
\text { Juan Cano } \\
\text { Jil/2) }^{(1 / 2)}\end{array}$ & & & & $\# 4$ \\
\hline & & $\begin{array}{l}\text { Jerónimo } \\
\text { de Castro }\end{array}$ & & & $\# 4$ \\
\hline \multirow[t]{2}{*}{ Teya } & [Alonso de Castro] & & & & $\# 4$ \\
\hline & & $\begin{array}{c}\text { Bernardina } \\
\text { Osorio }\end{array}$ & & & $\# 4$ \\
\hline Cacalchen & $\begin{array}{l}\text { [Francisco Tamayo/ } \\
\text { Sebastián Burgos]* }\end{array}$ & & & & $\# 4, \# 5$ \\
\hline \multirow[t]{2}{*}{$\begin{array}{c}\text { [Tekanto } \\
\text { y Tepakan] }\end{array}$} & Cristóbal Sánchez & & & & $\# 4, \# 5$ \\
\hline & & $\begin{array}{c}\text { Gobernador } \\
\text { [Velázquez de Gijón] }\end{array}$ & & & $\# 4, \# 5$ \\
\hline $\begin{array}{l}\text { Quitilcum } \\
\text { [Citilcum] }\end{array}$ & Pedro Hernández & & & & $\# 5$ \\
\hline Tixcochoh & $\begin{array}{l}\text { [Juan del Rey] } \\
\text { Gaspar del Rey }\end{array}$ & & & & \#5 \\
\hline Tixculum & Juan Bote & & & & \#5 \\
\hline $\begin{array}{c}{\left[\text { Suma }^{(1 / 2)}\right.} \\
\left.\text { Bokaba }^{(1 / 2)}\right]\end{array}$ & $\begin{array}{c}\text { [Antonio de] } \\
\text { Bohórquez }\end{array}$ & & & & $\# 5$ \\
\hline [Teya] & Alonso de Castro & & & & $\# 5$ \\
\hline \multirow[t]{4}{*}{ [Temax] } & Juan de Sosa & & & & $\# 5$ \\
\hline & & & & Dominguillo & \#5 \\
\hline & & $\begin{array}{c}\text { Marcos } \\
\text { Rodríguez }\end{array}$ & & & $\# 5$ \\
\hline & & Juan González & & & \#5 \\
\hline Telchac & [Corona Real] & $\begin{array}{c}\text { Pedro Gómez } \\
\text { Francisco } \\
\text { Pacheco }\end{array}$ & $\begin{array}{l}\text { Don Pedro } \\
\text { Pech }\end{array}$ & $\begin{array}{l}\text { Alonso Pech } \\
\text { Pablo Chu }\end{array}$ & $\# 5, \# 6$ \\
\hline Dzemul & [Corona Real] & $\begin{array}{l}\text { Francisco } \\
\text { Pacheco }\end{array}$ & & & $\# 6, \# 7$ \\
\hline
\end{tabular}

* Dos pueblos se llamaban Cacalchen: el primero, encomendado en Francisco Tamayo, se encontraba en la región Cehpech; el segundo estaba en la zona Cupul y su encomendero era Sebastián de Burgos. Ibid., fols. 32 y 33.

${ }^{28}$ La información que va entre corchetes está sacada de Manuela Cristina García Bernal, op. cit., pp. 491-542. 
Así pues, se puede observar que el territorio utilizado para cultivar el añil era más importante cuando participaban en el negocio personas del peso político del gobernador de Yucatán. No hay que olvidar, en efecto, que las cartas \#4 y 5 trataban esencialmente de la gestión de la estancia que Velázquez de Gijón poseía cerca de la ciudad de Mérida. Por otro lado, salvo la comunidad de Temozon, localizada en las inmediaciones de la villa de Valladolid, todos los pueblos de esta zona estaban situados al noreste de Izamal, lo que sugiere la existencia de una sectorización tanto en el cultivo de la tintórea como en la captación de la mano de obra maya. Y es que esa región servía, al parecer, de "reserva" de trabajadores para las estancias de añil implantadas no sólo allí sino también en las inmediaciones de Mérida. Eso explica por qué Cristóbal Sánchez planeaba enviar el grupo de indígenas que había reunido en Cacalchen al pueblo de Kanasin, situado a tan sólo unas cuantas leguas de esta ciudad (\#4). Esto coincide con las observaciones de Francisco Palomino, según el cual muchos encomenderos poseían "dos ingenios de dicho añil, uno en el pueblo de su encomienda y otro en la ciudad [de Mérida] y ambos [los] sustentan con sus encomendados", de modo que los mayas solían realizar desplazamientos de entre 12 y 15 leguas para satisfacer la demanda en trabajadores. ${ }^{29}$

Las cartas \#4 y 5 revelan, asimismo, que los españoles se habían organizado en una suerte de cooperativa para que la mano de obra indígena pudiese fluir fácilmente de una encomienda a otra, según las necesidades de la explotación añilera. Juan González afirma, así, que los 68 trabajadores reunidos por Cristóbal Sánchez procedían de Citilcum, Bokaba, Tixcochoh y Tixculum, "pueblos del diablo y de su hermano Pedro Hernández, Juan Bote, Gaspar del Rey y Bohórquez" (\#5). ${ }^{30}$ Así pues, los trabajadores se extraían de varias comunidades y, posteriormente, se redistribuía entre los socios, de forma que Fernando de Arceo, por ejemplo, debía recibir 12 indios para su propia estancia (\#4). A la cabeza de esta organización se encontraba Cristóbal Sánchez, designado juez de milpas de "la provincia de Tekanto" por el gobernador. Según Palomino, "a sombra de la vara de juez", este español se había "aprovechado así de los indios de su encomienda, sobre quienes tenía jurisdicción, como de los indios de los demás pueblos de aquella provincia, tomándolos para el beneficio de su añil y enviando también

\footnotetext{
${ }^{29}$ Id.

${ }^{30}$ Cabe subrayar que estos datos coinciden con los brindados por Manuela Cristina García Bernal, cuya investigación se apoya en la tasación oficial de 1549 y en las Relaciones Histórico Geográficas de 1579. Según esta historiadora, el pueblo de Citilcum (o Texan) era encomienda de Pedro Hernández Nieto y contaba con 320 tributarios en 1549. Por otro lado, Tixcochoh (o Tecalt) contaba con 310 tributarios en 1549 y estaba encomendado en Juan del Rey, pero en 1565 se traspasó al hijo de éste, Gaspar del Rey. Tixculum (o Texcolumo) era encomienda de Luis Hernández en 1549, pero, en 1579, ya lo era de Juan Bote. Finalmente, Bokaba y Suma fueron encomendados a Antonio de Bohórquez en 1565. Manuela Cristina García Bernal, op. cit., pp. 509 y 520-521. Dado que cada pueblo se corresponde con un encomendero, existe la posibilidad de que la expresión "del diablo y de su hermano" no se refiriera a ningún personaje histórico en concreto, sino que fuese utilizada para recalcar el carácter malvado de Pedro Hernández, hermano del diablo.
} 
indios para la estancia del dicho gobernador, de ciento en ciento y también a otras personas". ${ }^{31}$

En definitiva, el poder político estaba al servicio de los intereses privados, llegándose a crear cargos administrativos casi exclusivamente encaminados a gestionar las empresas de unos cuantos españoles. Cabe notar que el reparto de la mano de obra también se efectuaba en función del peso político y de los lazos de amistad de los socios, lo que generó tensiones en el seno del grupo dominante. Así lo sugiere el comentario de Cristóbal Sánchez, que lamentaba que a "Jerónimo de Castro le haya disgustado" dicho reparto (\#4). Algunos negocios se hicieron, incluso, sin el consentimiento de los encomenderos afectados, tal como ocurrió probablemente con Antonio de Bohórquez, cuyo encarcelamiento parece haber aprovechado el gobernador para captar a los trabajadores de su pueblo de encomienda, Bokaba.

Hasta los máximos responsables podían llegar a enfrentarse, al divergir sus propios intereses en el negocio. En efecto, la carta de Juan González era, en realidad, una amarga crítica de la gestión realizada por Cristóbal Sánchez. Y es que el gerente de la estancia de don Francisco Velázquez de Gijón insinuaba que el encomendero usaba gran parte de los trabajadores, que extraía de sus pueblos en nombre del gobernador, en sus propias estancias o en las de sus amigos: "según soy de malicioso, para mí tengo que tiene otros tantos [indios] Alonso de Castro y si no él [Cristóbal Sánchez] los tendrá”. Por consiguiente, Juan González recomendaba "escribir a Cristóbal Sánchez no haga merced de hacienda ajena", pues advertía que tantos excesos en la explotación de la mano de obra maya podrían provocar que "los frailes de aquella provincia, y aun los de acá, todo lo sepan" y que tuviesen "con esto ocasión alguna de hablar" (\#5).

Finalmente, las cartas \#6 y 7 muestran que los oficiales reales tampoco se mantuvieron ajenos a estos negocios y que no reparaban en usar a los indígenas de los pueblos administrados por la Corona para beneficiar sus propias estancias de añil. En efecto, según el defensor Palomino, Pedro Gómez y Francisco Pacheco habían hecho una estancia y un ingenio para el añil a media legua de la ciudad de Mérida y lo beneficiaban con los indios de la Real Corona, "trayéndolos de ciento en ciento, más y menos, de los pueblos de Telchac, Zemul y Kiní". Cabe recordar que en Yucatán la Corona española administraba 10 de los 179 pueblos registrados en la tasación de 1549 , con un total de 5920 tributarios, lo que representaba el $10.27 \%$ del total de la población tributaria de la provincia. ${ }^{32}$ Así, en la misiva \#7 el contador Francisco Pacheco solicitaba al gobernador de Telchac el envío de 40 o 60 indios y le pedía que "escribi[era] al [pueblo] de Dzemul que envíen otros 40" (carta \#7). No cabe duda de que estas frecuentes extracciones de mano de obra indígena redundarían en importantes pérdidas en la recolección

\footnotetext{
${ }^{31}$ Memorial de Francisco Palomino al rey, Mérida, 10 de noviembre de 1576, cit.

32 Los pueblos administrados por la Corona eran Campeche, Cusamá, Champotón, Kiní, Maní, Sabanal, Tecoh, Telchac, Ticul y Yaxkukul. Manuela Cristina García Bernal, op. cit., pp. 202-203 y 357-360.
} 
de los tributos destinados a la Real Hacienda. Por lo tanto, además de insistir en la dimensión legal del problema - obligación del rey de amparar a sus vasallos indígenas y necesidad de respetar las cédulas reales que prohibían que los encomenderos tuviesen tratos con sus encomendados-, en su memorial Francisco Palomino también hacía hincapié en el desfalco que estas continuas exacciones suponían para el Real Erario en término de recaudación de tributos. El defensor pretendía que el monarca proveyera que "de todo punto los encomenderos para cosa alguna no se sirvan de ellos [los indios] ni aun vayan a los pueblos de sus encomiendas" y que enviara a la provincia "una persona tal cual convenga que dé asiento en todo, porque mientras esto no se hiciere a todos no nos faltará trabajo". 33

\section{La alianza entre los gobernadores mayas y la oligarquía yucateca}

Ahora bien, este mecanismo de captación de la mano de obra indígena funcionaba en gran parte gracias a la cooperación de los gobernadores mayas, a quienes iban dirigidas cinco de las siete misivas. Y es que, todavía en el último cuarto del siglo xvl, las autoridades indígenas tradicionales seguían ejerciendo un control efectivo sobre los habitantes de sus comunidades. ${ }^{34}$ Bien es cierto que la relación entre los caciques y la oligarquía yucateca era asimétrica, puesto que los oficiales reales y los encomenderos, con el apoyo que les brindaban el gobernador Velázquez de Gijón y el juez de milpa Cristóbal Sánchez, tenían más poder no sólo político, sino también económico y coercitivo. No obstante, las misivas demuestran que el sistema no descansaba únicamente en la fuerza. Al contrario, se puede argüir que los españoles buscaron "interesar" a un determinado sector de la población maya, el cacicazgo, en sus negocios.

En efecto, los colonos trataron de coartar la voluntad de los gobernadores y principales indígenas mediante regalos, préstamos de dinero o, incluso, con favores políticos. Así, se menciona en tres ocasiones el vino que los encomenderos o los oficiales reales solían ofrecer a los caciques - "enviad un calabazo y llenároslo han de vino" (\#1), "confiad en que os envíe un poco de vino" (\#3) y "allí llevan la botija del vino para vos y los principales" (\#6)—. Por otro lado, el contador Francisco Pacheco y el tesorero Pedro Gómez prestaron 40 tostones a las autoridades de Telchac "para aderezar las andas" destinadas a transportar imágenes religiosas (\#6). ${ }^{35}$ Finalmente, Francisco Pacheco prometió al gobernador de Telchac, don Pedro Pech, que "sacar[ía] el mandamiento del gobernador [Velázquez de Gijón] para que todo el pueblo de Dzemul os obedezca y hagan lo

\footnotetext{
33 Memorial de Francisco Palomino al rey, Mérida, 10 de noviembre de 1576, cit.

${ }^{34}$ A este respecto, véase el trabajo reciente de Sergio Quezada, Maya Lords and Lordship: The Formation of Colonial Society in Yucatan, 1350-1600. Norman: University of Oklahoma Press, 2014.

${ }^{35}$ Andas, f. pl. : Angarillas con que se transporta a una persona o una imagen o paso de procesión.
} 
que vos les mandáredes" (\#7), de modo que se podía recompensar a los caciques convirtiendo a su comunidad en cabecera de una región. Tal vez fuera gracias a este tipo de estrategias que, según apunta Nancy Farriss, "en la época de la conquista española la familia Pech se las arregló para conseguir señoríos en 22 de los 25 pueblos comprendidos en la provincia de Cehpech [y que] en la década de 1570 todavía gobernaba en 11 de los pueblos de los que tenemos información". ${ }^{36}$

En todo caso, vemos que tanto los españoles, como algunos caciques mayas utilizaron la autoridad de su contraparte para acrecentar la suya propia: los primeros con el fin de ejercer un control más eficiente sobre la mano de obra indígena y los segundos para extender su poder político a comunidades adyacentes u obtener ventajas económicas. ${ }^{37}$ Para consolidar sus lazos con el cacicazgo maya, los españoles también se valieron de una retórica persuasiva, que contrasta con la violencia verbal que uno podría esperarse en vista del contexto de abusos que marcó, por lo general, las relaciones interétnicas en América. Así, en todas las cartas el nombre de los destinatarios viene seguido por el cargo que éstos ocupaban (gobernador, principal o escribano). Por otro lado, los autores se cuidaron de recurrir al "don" en señal de cortesía, pero también en reconocimiento de la nobleza de los caciques Martín Tun y Pedro Pech (\#1, 2, 6 y 7).

Incluso aparece la voluntad, por parte de los colonos, de marcar cierta igualdad de trato, ya que una misiva comienza con la interjección "Hijos" (\#6) y tres con la palabra "Hermano/s" (\#2, 3 y 7). Este término también se encuentra en las fórmulas de despedida junto con el posesivo "mi", que refuerza la idea de lazo fraternal entre emisores y destinatarios - "a mis hermanos Martín Tun y a los demás principales del pueblo de Xanaba" (\#2), "a mi hermano don Martín Tun, gobernador de Xanaba y a todos los principales" (\#3) y "a mi hermano don Pedro Pech, gobernador de Telchac" (\#7)—. Finalmente, las cartas se caracterizan por el uso de una retórica afectiva, dado que las emociones desempeñan un papel determinante en la comunicación persuasiva. ${ }^{38}$ Esta dimensión se expresa a través de frases hechas como "me holgué de saber todos tened salud, Dios os la dé como yo os la deseo" (\#1), "Nuestro Señor os dé mucha salud", "vuestro amo que mucho os quiere y ama" (\#3), "Cristo con todos" (\#6 y 7). Cabe notar que los términos "Jesús", "Dios", "Cristo" y "Nuestro Señor" también se repiten en varias ocasiones, lo que apunta a la asimilación, por parte de la élite maya, de la religiosidad católica popular o, al menos, de su expresión lexicalizada. Según William Hanks, este tipo de fórmulas hasta pasó a los discursos en lengua maya

${ }^{36}$ Nancy Farriss, La sociedad maya bajo el dominio colonial. La empresa colectiva de supervivencia. Madrid: Alianza Editorial, 1992, p. 383.

${ }^{37}$ Acerca de la legitimidad de los linajes mayas gobernantes en el periodo colonial, véase Tsubasa Okoshi Harada, "Vivir en dos mundos: los gobernantes mayas yucatecos del siglo xvı", Memorias del Cuarto Congreso Internacional de Mayistas, pp. 85-104. México: Universidad Nacional Autónoma de México, 2003.

${ }^{38}$ Rosario Fonseca y Leticia Prieto y Alizo, "Las emociones en la comunicación persuasiva: desde la retórica afectiva de Aristóteles”, Quórum Académico, VII (1): 78-95. 
yucateca, de modo que el autor utiliza el concepto de "maya reducido" para referirse al idioma hablado en la época colonial. ${ }^{39}$

En definitiva, el tono empleado por los españoles en las cartas difiere mucho del discurso oficial que se utilizaba en el imperio español, el cual se caracterizó por cierto paternalismo hacia los indios, definidos legalmente como personas miserables y necesitadas de amparo, retórica que los mismos indígenas reprodujeron en la mayoría de los escritos que destinaron a la Corona. ${ }^{40}$ Es interesante subrayar que en su memorial Francisco Palomino se apegó a esta imagen del indio sometido y temeroso que obedecía sin rechistar al poder abusivo de su tiránico amo, el encomendero, omitiendo por completo el proceso de coerción y soborno al que fueron sometidos los caciques mayas. ${ }^{41}$ No cabe duda de que esta visión maniquea de la compleja sociedad colonial y de la red de intereses que la recorría se debiera a la pretensión, por parte del defensor, de obtener una cédula que prohibiese la explotación del añil en la provincia.

De hecho, aunque este aspecto ha sido poco desarrollado por la historiografía, las alianzas entre la oligarquía española y parte de la élite indígena no debieron de ser tan infrecuentes en el periodo colonial. En Yucatán este tipo de acercamiento se produjo, por ejemplo, durante los juicios de idolatría de Maní en los años de 1560, ocasión en la cual muchos encomenderos defendieron a los caciques acusados de llevar a cabo prácticas idolátricas, y participaron en la campaña de detracción orquestada por el recién electo obispo fray Francisco de Toral en contra de fray Diego de Landa y sus correligionarios. Los colonos consiguieron ganarse la complicidad del defensor de indios Diego Rodríguez de Vivanco, que denunció con vehemencia los excesivos e injustos castigos impuestos a los mayas y que pidió al monarca la expulsión de los franciscanos de la provincia. ${ }^{42}$ Este conflicto revistió una clara dimensión política, ya que los encomenderos probablemente vieran en la "defensa" de los gobernadores mayas una oportunidad

${ }^{39}$ Hanks, Converting Words, p. 13

${ }^{40}$ Sobre la teoría del indio miserable, cf. Thomas Duve, "La condición jurídica del indio y su condición como persona miserabilis en el Derecho indiano", Un giudice e due leggi. Pluralismo normativo e conflitti agrari in Sud América, M. G. Losano (coord.), pp. 3-33. Milano: Giuffrè Editore, 2004, y Caroline Cunill, "El indio miserable: nacimiento de la teoría legal en la América colonial del siglo xvı", Cuadernos Intercambio, VIII: 229-248. Acerca del énfasis en la humildad que caracteriza los textos indígenas, véanse Luise M. Enkerlin, "Somos indios miserables: una forma de enfrentarse al sistema colonial", Antropología, XL: 49-54, Hanks, Converting Words, pp. 231-252 y Brian Owensby, Empire of Law and Indian Justice in Colonial Mexico, cap. 3. Stanford: Stanford University Press.

${ }^{41}$ Memorial de Francisco Palomino al rey, Mérida, 10 de noviembre de 1576, cit.

42 Inga Clendinnen, Ambivalent Conquest: Mayas and Spaniards in Yucatán, 1517-1570. Cambridge: Cambridge University Press, 1986. Carta del defensor Diego Rodríguez Vivanco al rey don Felipe II, suplicándole se dignara expulsar de las Indias a los frailes de la orden de San Francisco, Mérida, 8 de marzo de 1563, en Cartas de Indias, doc. LXIX. Madrid: Imprenta de Manuel G. Hernández, 1877, pp. 392-396. Según fray Diego de Landa, este defensor prefirió ser "amigo de agradar a quien más puede", antes que cumplir con la misión de proteger a los indios que le incumbía. Respuesta de fray Diego de Landa a la petición de Diego Rodríguez Vivanco, Mérida, 7 de febrero de 1563, Don Diego Quijada, alcalde mayor de Yucatán, 1561-1565, vol. I, p. 244, France Scholes y Eleonor Adams (eds.). México: Antigua Librería Robredo, 1938. 
para deshacerse tanto de unos religiosos molestos, como de un alcalde mayor que pretendía reducir el uso de tamemes para el transporte del tributo en la provincia. ${ }^{43}$

Aun así, la alianza entre la oligarquía española y los gobernadores mayas era frágil, como lo sugiere el hecho de que don Pedro Pech entregara al defensor las misivas que le habían enviado los oficiales reales. Los españoles debieron de ser conscientes de ello y es probablemente por esta razón que algunos decidieron asentarse en sus pueblos de encomienda con el fin de ejercer un control más estrecho sobre la mano de obra indígena y las mercancías. Francisco Palomino denunció este hecho en su memorial, insistiendo en la prohibición estipulada por la mencionada cédula del 4 de enero de $1575 .{ }^{44}$

Por otro lado, las cartas muestran que los españoles no dudaron en recurrir a intermediarios, cuyo principal encargo consistía en vigilar el correcto desenvolvimiento de las transacciones con los mayas. Algunos acompañaban las comitivas de mano de obra "porque [los indios] no se huyan en el camino que son malvados" (\#4), lo que revela la existencia de una dimensión coercitiva, aunque esté expresada de forma voluntariamente solapada. Una idea similar se desprende de la carta de Fernando de Arceo, quien ordenó a las autoridades indígenas de Xanaba que se le enviasen 10 indios "con un principal que tenga de ellos cuidado" (\#3). ${ }^{45}$ Por lo general, estos vigilantes se reclutaban entre los principales de los pueblos de donde procedían los trabajadores mayas, como lo sugiere esta frase de Cristóbal Sánchez: "Va de cada pueblo un principal con los indios que les cabe" (\#4). Las misivas \#1, 2 y 6 citan el nombre de algunos de aquellos intermediarios (Martín Dzabanal, Francisco Chan, Alonso Pech y Pablo Chu). El escribano Agustín Chan debió de desempeñar un papel similar, puesto que tanto Francisco de Arceo, como su hijo Fernando pidieron a las autoridades indígenas de Xanaba que le confiaran todos sus recados (\#1, 2 y 3). Finalmente, conviene notar que Juan González mencionó la presencia de un esclavo negro llamado Dominguillo. Pero parece que este personaje formaba parte de la casa y servidumbre del gobernador Velázquez de Gijón y que sólo se le encargaban misiones dentro de la ciudad

${ }^{43}$ Ibid., vol. I, pp. VIII-LX. Parece que este tipo de alianzas no eran casos aislados, dado que Ethelia Ruiz Medrano puso de manifiesto la fraguada entre las órdenes mendicantes, los encomenderos y los caciques del centro de México alrededor de la figura de Martín Cortés en 1560. Aquellos actores se unieron, en efecto, para luchar contra el peligro que suponía para sus intereses la ofensiva de la Monarquía para crear contrapoderes en sus dominios ultramarinos. Según la investigadora, los encomenderos hasta adoptaron parte de la indumentaria y de los símbolos de poder indígenas tradicionales. Estas observaciones entroncan con las relativas a las cartas estudiadas aquí, al mostrar la capacidad de adaptación y las concesiones que estaban dispuestos a realizar los españoles con respecto a sus contrapartes indígenas (Ruiz Medrano, "Fighting Destiny: Nahua Nobles and the Friars in the Sixteenth-Century Revolt of the the Encomenderos against the King", Negotiation within Domination. New Spain's Indian Pueblos Confront the Spanish State, pp. 45-78, Susan Kellogg y Ethelia Ruiz Medrano (eds.). Boulder: University Press of Colorado, 2010).

${ }_{44}^{44}$ Memorial de Francisco Palomino al rey, Mérida, 10 de noviembre de 1576, cit.

${ }^{45}$ Las cursivas son mías. 
de Mérida, como, por ejemplo, la de ir a casa del español Marcos Rodríguez para buscar cal, hierro y aderezos que, luego, se enviarían a los indios para arreglar una noria (\#5). ${ }^{46}$

Otros intermediarios mayas estaban encargados de transportar el dinero que se había de entregar a los interesados en pago de sus servicios, de modo que Francisco Chan llevaba "600 cacaos para los dos indios que fueron a Çequi por la manteca" (\#2). ${ }^{47} \mathrm{Y}$ es que resulta muy interesante comprobar que los españoles instauraron un complejo sistema de remuneración para los indígenas que participaban en sus negocios, con pagas que se calculaban según el grado de responsabilidad de cada uno. Así, pues, Cristóbal Sánchez recomendaba al gobernador Velázquez de Gijón que diese dos reales "a este principal que los lleve hasta allí [Mérida] a entregarlos a Vuestra Merced”. En cambio, siempre según él, "basta[ba] que Vuestra Merced les mande dar a cada uno 120 cacaos" a los trabajadores indios que conformaban la comitiva (\#4). Por su lado, Francisco y Fernando de Arceo abonaban 280 cacaos a los mayas que trabajaban en sus estancias y 300 a los "que fueron a Çequi por la manteca" (\#2). Se puede observar, por lo tanto, que esta remuneración se aproximaba mucho a lo que cobraban los indios que realizaban obras de interés general en la ciudad de Mérida, puesto que Francisco Palomino afirmó en 1576 que los mayas que trabajaban en la catedral recibían 300 cacaos semanales. Según el defensor, este salario estaba muy por debajo de los tres reales de plata estipulados por la legislación, pues tal cantidad de cacao ni siquiera equivalía a dos reales. ${ }^{48}$

Finalmente, cabe subrayar que, si bien el presente conjunto documental es excepcional debido a las circunstancias en las que se conservó, no por ello ha de concluirse que los intercambios epistolares entre mayas y españoles fueran escasos en la época. Al contrario, varios elementos parecen indicar que se trataba de una práctica relativamente común en la península. Así lo sugiere el hecho de que numerosos pueblos, tales como Xanaba o Telchac, solían recibir noticias por esta vía. Francisco Palomino señala en su memorial que el teniente general del gobernador, el bachiller Tinoco de Carvajal, también acostumbraba enviar "mandamientos y cartas para los caciques para que le d[ieran] indios" que trabajasen en la estancia de añil que éste poseía a un cuarto de legua de Mérida. ${ }^{49}$ Estos intercambios se efectuaban, además, con regularidad, ya que tanto Francisco de Arceo y su hijo Fernando como los oficiales reales mandaron varias cartas a los gobernadores in-

\footnotetext{
46 Sobre la presencia y el papel de los africanos en América, véase Matthew Restall y Jane Landers (eds.), "The African Experience in Early Spanish America", The Americas, LVII (2): 167-170.

47 Es probable que se trate de Çique o Saci, encomienda de Baltasar Gallego. Manuela Cristina García Bernal, op. cit., p. 41.

48 Según Francisco Palomino, la carga de cacao de 1.800 granos se compraba en Yucatán en 10 u 11 reales, de modo que tres reales debían equivaler a aproximadamente 500 cacaos. Estos datos concuerdan con los del contrato de los indios de Dzilam y Conil en el que se estipuló que un tostón de a cuatro reales equivalía a 483 cacaos. Cunill, Los defensores de indios, p. 276.

49 Idem.
} 
dígenas en unos cuantos días. Por otro lado, aunque sólo se conservaron las cartas de los españoles, conviene recalcar que los mayas también respondían a sus interlocutores por vía epistolar. Es lo que indican dos frases en que Francisco de Arceo y Francisco Pacheco, respectivamente, se referían a unas misivas que les habían enviado los indígenas: "Escribís que [los indios] no tienen comida" (\#1) y "Hermano, recibí vuestra carta" (\#7). Asimismo, estos negocios fomentaron la comunicación epistolar entre las comunidades mayas, de modo que el contador Pacheco recomendó a los principales de Telchac que escribieran a los de Dzemul para pedirles indios - "Y escribi[d] vos al de Dzemul que envíen otros cuarenta [indios]"- - Estos elementos invitan a interrogarse sobre la posible existencia de una correspondencia intercomunitaria en el Yucatán del siglo xvı. ${ }^{50}$

Es evidente que estos intercambios implicaban que tanto emisores como receptores compartían el mismo idioma y estaban alfabetizados. ${ }^{51}$ Sin embargo, no era forzosamente el gobernador indígena quien hablaba el castellano o el que sabía leer y escribir. Así, por ejemplo, aunque el principal destinario de las misivas del encomendero Francisco de Arceo y de su hijo Fernando fuese el gobernador de Xanaba, don Martín Tun, ambos autores hicieron especial hincapié en el escribano Agustín Chan, a quien se había de confiar todas sus "encomiendas" $(\# 2,3)$. Es probable, por consiguiente, que Agustín Chan fuese encargado de leer y de traducir el contenido de las cartas dirigidas al cacique maya y que este papel privilegiado le permitiera granjearse la confianza de los españoles. Pero la comunicación interétnica también se vio facilitada por el bilingüismo de algunos colonos. Francisco Palomino advierte, en efecto, que los españoles tenían "tanta mano" sobre los naturales que "lo que quisieren que digan eso dirán y en especial los que tienen a los encomenderos lenguas", esto es, los que hablaban el maya yucateco. ${ }^{52} \mathrm{Y}$ es que Brain y Nesvig recuerdan que, desde fechas tempranas, muchos colonos aprendieron los idiomas autóctonos de las regiones donde estaban asentados con el fin de alentar el buen desempeño de sus negocios. ${ }^{53}$

En Yucatán, destaca el caso de Francisco Hernández, vecino de la villa de Valladolid, acusado de difamar a los religiosos entre los mayas de Champotón en la década de 1550. La preocupación de los franciscanos era mayor ya que este encomendero era "naguatlato de los mejores que hay en esta provincia". ${ }^{54}$ En realidad, el proceso de "mayanización" de los españoles se dio de forma bastante natural en esa provincia, puesto que los hijos de los colonos solían ser criados

\footnotetext{
${ }^{50}$ Acerca de la comunicación intercomunitaria en el Centro de México, véase David E. Távarez, "La idolatría letrada: un análisis comparativo de textos clandestinos rituales y devocionales en comunidades nahuas y zapotecas, 1613-1654", Historia Mexicana, XLIX (2): 197-252.

51 Caroline Cunill, "La alfabetización de los mayas yucatecos y sus consecuencias sociales (15451580)", Estudios de Cultura Maya, XXXI: 163-192.

${ }^{52}$ Memorial de Francisco Palomino al monarca, Mérida, 10 de noviembre de 1576, cit.

53 Brain, "Aprendizaje”, pp. 283-285 y Nesvig, "Spanish Men”, pp. 740-741.

54 Proceso contra Francisco Hernández ante la Inquisición ordinaria por ofensas a los religiosos franciscanos, 1556-1562. Ignacio Rubio Mañé, Archivo de la historia de Yucatán, Campeche y Tabasco, vol. II, pp. 7. México: Imprenta Albina, 1942.
} 
por nodrizas mayas, llamadas en nahua chichiguas, quienes les transmitían su idioma. ${ }^{55} \mathrm{~A}$ este respecto, es interesante notar que la segunda generación, tanto entre los mayas, como entre los españoles, desempeñó un papel fundamental en la comunicación interétnica. La primera carta muestra, por ejemplo, que a los intercambios epistolares se sumaban frecuentes encuentros protagonizados por el hijo del gobernador maya de Xanaba, Baltasar Tun ("aquí [Mérida] vino vuestro hijo Baltasar Tun y Martín Dzabanal”). El hijo de Francisco de Arceo, Fernando, aparece, a su vez, como el principal interlocutor de los indígenas de Xanaba, ya que es el autor de dos de las tres cartas interceptadas por el defensor Francisco Palomino (\#2 y 3).

\section{Consideraciones finales}

Las siete cartas esclarecen el uso que hicieron los españoles tanto del espacio, como de la mano de obra indígena para explotar el añil en la provincia de Yucatán. Muestran que éstos no se contentaron con utilizar ilegalmente a los mayas de sus propios pueblos de encomienda, sino que también se valieron de los indios de encomiendas ajenas. Así, en la década de 1570, los colonos interesados en la producción del añil conformaron una suerte de cooperativa, cuya cúspide ocupaba el gobernador don Francisco Velázquez de Gijón, con el apoyo del encomendero y juez de milpa Cristóbal Sánchez, que controlaba los flujos de trabajadores mayas desde el pueblo de Teya. Este sistema generó fuertes tensiones en el seno mismo de la oligarquía local, debido al carácter parcial del acceso a la mano de obra indígena. Pero el aspecto más interesante de las cartas gira en torno al papel que desempeñaron los caciques mayas en el proceso de captación y control de los trabajadores. En efecto, estos documentos revelan que los españoles prefirieron la colaboración con los gobernadores mayas antes que la coerción, siempre que fuese posible. $Y$ es que el doble poder, interno y externo, de las autoridades indígenas — control de la mano de obra y posibilidad de recurrir al sistema de justicia colonial para denunciar los abusos cometidos por los dueños de las estancias- explica por qué los colonos se esforzaran por seducirlos con regalos, alicientes económicos y favores políticos.

El discurso deferente con el que los encomenderos y los oficiales reales se dirigían a sus interlocutores indígenas tampoco fue ajeno a este esfuerzo por ganarse la voluntad de los caciques para que éstos apoyaran los intereses de la oligarquía yucateca. No obstante, el hecho de que uno de los gobernadores indígenas entregara las misivas al defensor Francisco Palomino pone de manifiesto

55 Nancy Farriss, “Conquista y cultura: los mayas de Yucatán”, Descubrimiento, conquista y colonización de América a quinientos años, pp. 208-211, Carmen Bernand (comp.). México: Fondo de Cultura Económica, 1994. Véase también Manuela Cristina García Bernal, “Los servicios personales en Yucatán durante el siglo xvı", Revista de la Universidad Autónoma de Yucatán, XIX: 79-81. 
los límites del intento, puesto que ambos grupos no dudaron en enfrentarse cuando sus intereses, tanto económicos como políticos. dejaban de coincidir. En consecuencia, si bien no aparece explícitamente en las misivas, no cabe duda que la coerción, que se ejercía mediante los intermediarios encargados de controlar las transacciones, explica la posición de ambigüedad que ocupaban los gobernadores mayas en esta compleja red de intercambios. En definitiva, se puede arguiir que la comunicación privada permite aprehender una realidad mucho más rica de lo que generalmente dejan entrever los discursos oficiales, debido a las orientaciones políticas que los condicionan y las subsiguientes simplificaciones que los definen, ofreciéndonos en muchas ocasiones una visión maniquea de las fluctuantes alianzas multiétnicas que se forjaban en el seno de la sociedad colonial. 


\section{APÉNDICE DOCUMENTAL}

Este es un trasunto de unas cartas que los de dentro en ellas contenidas escribieron a los caciques. Va para que su Majestad lo vea [AGI, México 100, R. 4]. ${ }^{56}$

\section{Carta \#1}

Jesús María. Aquí vino vuestro hijo Baltasar Tun y Martín Dzabanal y me holgué de saber todos tened salud. Dios os la dé como yo os la deseo. Estaba Fernando de Arceo aguardando los diez indios para el servicio del añil como allá os lo habrá dicho el padre fray Gaspar. Escribís que no tienen comida. Vengan el lunes aquí amanecer pues ya viene maíz de esa provincia para sus encomenderos y unos pocos de elotes que me enviasteis; mas era maíz que elotes porque se hizo pan de ello; que no tenemos ningún maíz en casa que, por daros las sesenta cargas a tostón, lo he comprado cada carga a tres tostones y lo hice por haceros placer vista vuestra necesidad y, pues ahora ya no tengo ningún maíz, ruego os mucho que de aquí a quince días me enviéis cuarenta cargas a cuenta del tributo de lo más seco que hubiere y en esto me haréis placer. En lo del tributo el tiempo es ya acabado, es menester que también venga de aquí a quince días que sea muy bueno y muy benzudo porque ya en Acanceh estante yendo y enviad un calabazo y llevaroslo ${ }^{57}$ han de vino. Trajeron diez gallinas de Castilla, faltan cinco, porque allá están a cacao, para dieciséis gallinas trajeron cincuenta cacaos que es una gallina, faltan cinco. Habéislo hecho muy mal a cabo de dos meses y también trajeron diez del tributo a cabo de cuarenta días. Habéislo hecho muy mal porque Bocaba no ha faltado de enviar sus gallinas a sus encomenderos. Enviadme veinte gallinas del tributo con el maíz que os envío a pedir. A Agustín Chan daréis mis encomiendas, que le ruego mucho ponga diligencia en que se me envíe como digo de aquí a quince días las veinte cargas de maíz y las veinte gallinas y los diez indios cada lunes para Fernando de Arceo para lo del añil y con tanto no más. De Mérida, donde quedo a lo que mandáredes. Vuestro amo, Francisco Arceo. Es para don Martín Tun, gobernador de Xanaba y para Agustín Chan, escribano y para los demás principales del dicho pueblo de Xanaba.

\section{Carta \#2}

Hermanos, estos indios acabaron de trabajar hoy viernes porque dijeron se les había acabado el pozol y a esta causa no los quise detener. Van pagados todos a doscientos y ochenta cacaos cada uno. Haced que hagan todos sus milpas que ahora hasta de aquí a tres meses no es menester indios. Lleva Francisco Chan seiscientos cacaos para los dos indios que fueron a Çequii ${ }^{58}$ por la manteca. Mandaréis que a cada uno se le dé a trescientos cacaos. Mandaréis que traigan veinte

\footnotetext{
${ }^{56}$ Se ha modernizado la ortografía y se ha agregado la puntuación con el fin de facilitar la lectura de los textos.

${ }^{57}$ Aquí es posible que el escribano cometiera un error al copiar el texto y que la palabra original fuese "llenároslo" en vez de llevároslo".

${ }^{58}$ Es probable que se trate del pueblo de Çique o Saci, encomienda de Baltasar Gallego. Manuela Cristina García Bernal, op. cit., p. 41.
} 
gallinas del tributo y las mantas. Haced que vayan muy delgadas y que se acaben para la Pascua. Y Nuestro Señor os dé la salud que os deseo. De esta ciudad, abril, doce de 1576 años, a lo que mandáredes, Fernando de Arceo. Encomendadme a todos los principales y a Agustín Chan mis encomiendas y que tengo mucho deseo de verle. Traigan el maíz después de Pascua porque no hay maíz en casa y una botija de miel y mira que no hagáis otra cosa. A mis hermanos Martín Tun y los demás principales del pueblo de Xanaba.

\section{Carta \#3}

Hermanos, mucho me he holgado de que Nuestro Señor os haya dado tan buen año. Dadle muchas gracias por ello. Lo que al presente tengo que rogaros es que de aquí a dos semanas me enviéis siempre diez indios con un principal que tenga de ellos cuidado y esto os ruego mucho que siempre me los enviéis pues de aquí adelante tendrán que comer y pasada nuestra señora de agosto podréis comenzar a enviarme los indios y enviad ${ }^{59}$ en que os envíe un poco de vino y encomendadme a todos los principales y a Agustín Chan el escribano y si hubiéredes menester alguna cosa me avisad. Nuestro Señor os de mucha salud. De esta ciudad, sábado, vuestro amo que mucho os quiere y ama. Fernando de Arceo. A mi hermano don Martín Tun, gobernador de Xanaba y a todos los principales.

Sacado, corregido y concertado fue este dicho traslado de las cartas originales por mí, Francisco de Orozco, notario público apostólico de este Obispado de Yucatán, Cozumel, y Tabasco, estando en la ciudad de Mérida en el dicho Obispado, a 24 de octubre de 1576 años, siendo presentes por testigos Alonso Palomino el Mozo y Francisco de Acebedo estantes en la dicha ciudad. De mandamiento del muy Ilustre y Reverendo Señor don fray Diego de Landa, mi señor obispo de este dicho Obispado del Consejo de su Majestad y de pedimento de Francisco Palomino defensor de los naturales de este Obispado, en cuyo poder quedan los originales para informar de ello a Su Majestad y a su Real Consejo y que no ha hecho manifestación de ellos, ni pide este testimonio ante los escribanos reales de esta ciudad por los inconvenientes que de manifestarlo podría suceder y porque podrían impedirlo y buscar medios para que lo susodicho no tuviese efecto por lo cual su Señoría Reverendísima me mandó diese este testimonio en fe de lo que hice aqueste mi signo que es a tal en testimonio de verdad. Francisco de Orozco, notario público apostólico.

\section{Carta \#4}

Muy magnífico señor, el portador de ésta lleva sesentaiocho indios de servicio y tantos dice envían por memoria los caciques a su buena verdad que yo no los he visto sólo los tengo avisados y bien que se junten en Cacalchen para que todos juntos se vayan derechos a Tezomon. Y a este principal que los lleve hasta allí a entregarlos a Vuestra Merced, mandarle ha Vuestra Merced dar por su trabajo dos reales. Va de cada pueblo un principal con los indios que les cabe porque no se huyan en el camino que son malvados. A estos bastará que Vuestra Merced les

\footnotetext{
${ }^{59}$ Es probable que la palabra original fuese "confiad" en vez de "enviad".
} 
mande dar a cada uno 120 cacaos. Yo haré por enviar la semana que viene más indios. Si en otra cosa puedo, Vuestra Merced mande y será servido. Al señor gobernador me hará Vuestra Merced merced de darle mis besamanos y que me ha llegado al alma que Jerónimo de Castro le haya disgustado porque deseo que todos mis deudos le sirvan, mas debe haber ruines de por medio. Pero yo doy la palabra que al fin se ha de hacer lo que yo pretendiere o no quedará pedazo de mí, pues no le tengo de faltar de aquí a que muera. Bernardina Osorio besa las manos a Vuestra merced y nuestro Señor la muy magnífica persona guarde muchos años como yo, servidor de Vuestra Merced, deseo. De Teya, sábado, muy magnífico señor besa las manos a Vuestra Merced su muy servidor Cristóbal Sánchez. A Fernando de Arceo me hará Vuestra Merced merced de mandarle enviar doce indios con la que va con esta. Los doce indios que a Fernando de Arceo se enviaren suplico a Vuestra Merced que sea con persona de recaudo y tenga vuestra merced el dicho quien reciba los indios en Kanasin.

\section{Carta \#5}

Muy Ilustre señor la de la vuelta me escribió Cristóbal Sánchez y con ella envió sesenta y cinco indios y con ellos un principal de su pueblo. ${ }^{60}$ Todos ellos son de Quitilcum, Bocaba, Tixcochoh y Tixculum, pueblos del diablo y de su hermano Pedro Hernández, Juan Bote, Gaspar del Rey y Bohórquez. El principal que los trujo me dijo que en nombre de vuestra merced y para desherbar su milpa de añil se sacaron de los pueblos. Y quiera Dios que solos estos hayan salud que, según soy de malicioso, para mí tengo que tiene otros tantos Alonso de Castro y sino él los tendrá. ${ }^{61}$ Si Vuestra merced es servido, bien será escribir a Cristóbal Sánchez no haga merced de hacienda ajena que no es posible sino que los frailes de aquella provincia y aun los de acá todo lo sepan y ellos y sus contemplativas tendrán con esto ocasión alguna de hablar. Suplico a Vuestra Merced, aunque todo se quede por desherbar, no vengan más indios por mano de tal hombre pues tan mal lo hace y si Vuestra Merced fuere servido que se lo escriba me mande avisar y si podré enviar por los cuarenta de Cacalchen para la semana venidera porque con lo uno y lo otro despaché un principal. A Fernando de Arceo envié diez y ocho porque no diga que me ate a la letra que manda que le den doce con los demás y los de Juan de Sosa se hará siendo Dios servido razonable hacienda y mudaremos las casas que es lo más necesario. Mañana irán por cal y por el hierro y aderezos de la noria. Mandará vuestra merced a Dominguillo vaya a casa de Marcos Rodríguez por ella. Criado de vuestra merced, González.

Sacado, corregido y concertado fue este dicho traslado de las cartas originales por mí, Francisco de Orozco [...]. ${ }^{62}$

${ }^{60}$ Esta cifra no difiere de la precedente, que brindó Cristóbal Sánchez, ya que a los 65 trabajadores indígenas había que sumar a los principales que los acompañaban en la comitiva.

${ }^{61}$ Es probable que el autor de la misiva se refiriera a Cristóbal Sánchez.

62 Dado que este apartado, presente al final del primer grupo de cartas, se repite aquí de forma idéntica, no lo volveré a copiar íntegro. 


\section{Carta \#6}

Hijos, allí lleva Alonso Pech indio, los 40 tostones que pedís que os prestemos para aderezar las andas. Tendréis cuidado de que se aderecen muy bien pues es cosa de Dios y pagárnoslos para cuando decís. También recibimos las seis cargas de maíz. Allí llevan la botija del vino para vos y los principales. Allá enviamos un indio Pablo Chu que para que nos enviásedes indios para limpiar el añil. Por vida vuestra que los enviéis cada semana que presto se acabará de limpiar. Y Cristo con todos. De Mérida, a seis de septiembre de 1576 años. A lo que mandáredes, Pedro Gómez, tesorero, Francisco Pacheco, contador. Para don Pedro Pech gobernador de Telchac y principales.

\section{Carta \#7}

Hermano, recibí vuestra carta y doce gallinas faltan ocho para veinte. Enviádmelas que sean buenas. Yo sacaré el mandamiento del gobernador para que todo el pueblo de Dzemul os obedezca y hagan lo que vos les mandáredes. Enviadnos otros cuarenta o sesenta indios que los hemos menester. Y escribi[d] vos al de Dzemul que envíen otros cuarenta y Cristo con todos. De Mérida, hoy jueves, vuestro hermano Francisco Pacheco, contador. A mi hermano don Pedro Pech gobernador de Telchac.

Sacado, corregido y concertado fue este dicho traslado de las cartas originales por mí, Francisco de Orozco [...]. ${ }^{63}$

63 Por la razón arriba mencionada, no volveré a copiar este párrafo aquí. 


\section{BIBLIOGRAFÍA}

Brain, Cecilia

2010 "Aprendizaje de lenguas indígenas por parte de españoles en Nueva España en los primeros cien años después de la conquista", Colonial Latin American Review, XIX (2): 279-300.

Cartas de Indias

1877 Madrid: Imprenta de Manuel G. Hernández.

Clendinnen, Inga

1986 Ambivalent Conquest: Mayas and Spaniards in Yucatán, 1517-1570. Cambridge: Cambridge University Press.

Cunill, Caroline

2008a "Negocios y justicia: Francisco Palomino, defensor de los mayas de Yucatán (1569-1586)", Temas americanistas, XX: 1-26.

2008b "La alfabetización de los mayas yucatecos y sus consecuencias sociales (1545-1580)", Estudios de Cultura Maya, XXXI: 163-192.

2011 "El indio miserable: nacimiento de la teoría legal en la América colonial del siglo xvı", Cuadernos Intercambio, VIII: 229-248.

2012a Los defensores de indios de Yucatán y el acceso de los mayas a la justicia colonial, 1540-1600. México: Universidad Nacional Autónoma de México, Centro Peninsular en Humanidades y Ciencias Sociales.

2012b "Los defensores de indios de la alcaldía mayor de Tabasco (siglo xvI)", Historia Mexicana, LXII (2): 551-590.

Chevalier, François

1976 El añil, su artesanía actual en el Departamento de Chalatenango. San Salvador:

Departamento de Investigaciones del Patrimonio Cultural.

Duve, Thomas

2004 "La condición jurídica del indio y su condición como persona miserabilis en el Derecho indiano", Un giudice e due leggi. Pluralismo normativo e conflitti agrari in Sud América, pp. 3-33, M. G. Losano (coord.). Milano: Giuffrè Editore.

Enkerlin, Luise M.

1993 "Somos indios miserables: una forma de enfrentarse al sistema colonial", Antropología, XL: 49-54.

Farriss, Nancy

1992 La sociedad maya bajo el dominio colonial. La empresa colectiva de supervivencia. Madrid: Alianza Editorial.

1994 “Conquista y cultura: los mayas de Yucatán”, Descubrimiento, conquista y colonización de América a quinientos años, pp. 208-211, C. Bernand (comp.). México: Fondo de Cultura Económica.

Fonseca, Rosario y Leticia Prieto y Alizo

2010 "Las emociones en la comunicación persuasiva: desde la retórica afectiva de Aristóteles", Quórum Académico, VII (1): 78-95. 
Foucault, Michel

1970 El orden del discurso. Barcelona: Tusquets.

Franco Figueroa, Mariano

2011 "Cartas de mujeres en documentos americanos coloniales", Boletín de Filología, XLVI (2): 59-84.

García Bernal, Manuela Cristina

1977 "Los servicios personales en Yucatán durante el siglo xvı", Revista de la Universidad Autónoma de Yucatán, XIX: 79-81.

1978 Población y encomienda en Yucatán bajo los Austrias. Sevilla: Escuela de Estudios Hispanoamericanos.

1992 "Indios y españoles en Yucatán: Utopía y realidad del proyecto colonizador", Congreso de Historia del Descubrimiento, vol. II, pp. 387-427. Madrid: Real Academia de Historia.

Hanks, William F.

2010 Converting Words. Maya in the Age of the Cross. Berkeley: University of California Press.

León Cázares, María del Carmen

1988 Un levantamiento en nombre del Rey Nuestro Señor. Testimonios indígenas relacionados con el visitador Francisco Gómez de Lamadriz. México: Universidad Nacional Autónoma de México, Instituto de Investigaciones Filológicas, Centro de Estudios Mayas (Serie Cuadernos, 18).

Lockhart, James

1991 Nahuas and Spaniards: Postconquest Mexican History and Philology. Stanford: Stanford University Press.

Lockhart, James y Enrique Otto

1976 Letters and People of the Spanish Indies. Cambridge: Cambridge University Press.

Lockhart, James y Frances Karttunen

$1976 \quad$ Nahuatl in the Middle Years: Language Contact Phenomena in Texts of the Colonial Period. Berkeley: University of California Press.

Martínez, José Luis

1992 El mundo privado de los emigrantes en Indias. México: Fondo de Cultura Económica.

Miller, Sara

1985 "Francisco Palomino, protector y defensor de los indígenas", Mesoamérica, IX: 133-153.

Nesvig, Martín

2012 "Spanish Men, Indigenous Language, and the Informal Interpreters in Postcontact Mexico”, Ethnohistory, LIX (4): 739-764. 
Oesterreicher, Wulf

2004 "Textos entre inmediatez y distancia comunicativas. El problema de lo hablado escrito en el Siglo de Oro”, Historia de la lengua española, pp. 729-769, R. Cano Aguilar (coord.). Barcelona: Ariel.

Oesterreicher, Wulf, Eva Stoll y Andreas Wesch (eds.)

1998 Competencia escrita, tradiciones discursivas y variedades lingüísticas. Aspectos del español europeo y americano en los siglos XVI y XVII. Tübingen: Nar.

Okoshi Harada, Tsubasa

2000 "Los Xiu del siglo xvı: una lectura de dos textos mayas coloniales", Mesoamérica, XXXIX: 225-253.

2003 "Vivir en dos mundos: los gobernantes mayas yucatecos del siglo xvı", Memorias del Cuarto Congreso Internacional de Mayistas, pp. 85-104. México: Universidad Nacional Autónoma de México, Instituto de Investigaciones Filológicas, Centro de Estudios Mayas.

Otto, Enrique

1988 Cartas privadas de emigrantes a Indias, 1540-1616. Sevilla: Escuela de Estudios Hispanoamericanos.

Owensby, Brian P.

2008 Empire of Law and Indian Justice in Colonial Mexico. Stanford: Stanford University Press.

Quezada, Sergio

1993 Pueblos y caciques yucatecos, 1550-1580. México: El Colegio de México.

2014 Maya Lords and Lordship: The Formation of Colonial Society in Yucatan, 13501600. Norman: University of Oklahoma Press.

Quezada, Sergio y Tsubasa Okoshi Harada

2001 Los papeles de los Xiu de Yaxá, Yucatán. México: Universidad Nacional Autónoma de México, Instituto de Investigaciones Filológicas, Centro de Estudios Mayas (Serie Fuentes para el Estudio de la Cultura Maya, 15).

Relaciones Histórico-Geográficas de la Gobernación de Yucatán

2008 Vol. I, $2^{a}$ ed., Mercedes de la Garza, Ana Luisa Izquierdo, María del Carmen León y Tolita Figueroa (eds.), María del Carmen León (paleogr.). México: Universidad Nacional Autónoma de México, Instituto de Investigaciones Filológicas, Centro de Estudios Mayas (Serie Fuentes para el Estudio de la Cultura Maya, 1).

Restall, Matthew

1997 The Maya World. Yucatec Culture and Society, 1550-1850. Stanford: Stanford University Press.

2003 "A History of New Philology and the New Philology in History", Latin American Research Review, XXXVIII (1): 113-134. 
Restall, Matthew y Jane Landers

2000 "The African Experience in Early Spanish America", The Americas, LVII (2): 167-170.

Rubio Mañé, J. Ignacio

1942 Archivo de la historia de Yucatán, Campeche y Tabasco. México: Imprenta Albina, 2 vols.

Rubio Sánchez, Manuel

1976 Historia del añil o xiquilite en Centroamérica. San Salvador: Dirección de Publicaciones del Ministerio de Educación.

Ruiz Medrano, Ethelia

2010 "Fighting Destiny: Nahua Nobles and the Friars in the Sixteenth-Century Revolt of the the Encomenderos against the King”, Negotiation within Domination. New Spain's Indian Pueblos Confront the Spanish State, pp. 45-78, Susan Kellogg y Ethelia Ruiz Medrano (eds.). Boulder: University Press of Colorado.

Ruz, Mario Humberto

1979 "El añil en el Yucatán del siglo xv”", Estudios de Cultura Maya, XII: 111-156.

1994 “La última conquista: Tecpan Cimatán, 1564”, Tierra y Agua, 4: 7-23.

Sarabia Viejo, María Justina

1994 La grana y el añil. Técnicas tintóreas en México y América Central. Sevilla: Publicaciones de la Escuela de Estudios Hispanoamericanos.

Scholes, France V. y Eleonor Adams (eds.)

1938 Don Diego Quijada, alcalde mayor de Yucatán, 1561-1565. México: Antigua Librería Robredo.

Schwaller, Robert C.

2012 "The Importance of Mestizos y Mulatos as Bilingual Intermediaries in Sixteenth-Century New Spain”, Ethnohistory, LIX (4): 713-738.

Solís Robleda, Gabriela

2003 Bajo el signo de la compulsión: el trabajo forzoso en el sistema colonial yucateco, 1540-1730. México: Instituto Nacional de Antropología e Historia y Centro de Investigaciones y Estudios Superiores en Antropología Social.

Távarez, David Eduardo

1999 "La idolatría letrada: un análisis comparativo de textos clandestinos rituales y devocionales en comunidades nahuas y zapotecas, 1613-1654”, Historia Mexicana, XLIX (2): 197-252.

Warren, J. Benedict

1984 La administración de los negocios de un encomendero de Michoacán. México: Secretaría de Educación Pública. 
Yannakakis, Yanna

2008

The Art of Being in-Between. Native Intermediaries, Indian Identity, and Local Rule in Colonial Oaxaca. Durham y Londres: Duke University Press.

2012 "How Did They Talk to One Another? Language Use and Communication in Multilingual New Spain”, Ethnohistory, LIX (4): 667-674. 